\title{
The subcellular distribution of cyclin-D1 and cyclin-D3 within human islet cells varies according to the status of the pancreas donor
}

\author{
Kazuto Taniguchi ${ }^{1} \cdot$ Mark A. Russell $^{1}$. \\ Sarah J. Richardson ${ }^{1} \cdot$ Noel G. Morgan ${ }^{1}$
}

Received: 6 March 2015 / Accepted: 15 May 2015 / Published online: 9 June 2015

(C) Springer-Verlag Berlin Heidelberg 2015

\begin{abstract}
Aims/hypothesis In humans, the rate of beta cell proliferation declines rapidly during the postnatal period and remains low throughout adult life. Recent studies suggest that this may reflect the distribution of cell cycle regulators which, unusually, are located in the cytosolic compartment of beta cells in islets isolated from adults. In the present work, we examined whether the localisation of cyclin-D molecules is also cytosolic in the islet cells of pancreatic samples studied in situ.

Methods Immunohistochemical approaches were employed to examine the subcellular localisation of cyclin-D1, -D2 and -D3 in human pancreatic samples recovered either from heart-beating donors or post mortem. Immunofluorescence methods were used to reveal the cellular localisation of cyclin-D1 and -D3.

Results The distribution of cyclin-D2 was invariably cytosolic in islet cells, whereas the localisation of cyclin-D1 and -D3 varied according to the status of the donor. In pancreatic sections from heart-beating donors these molecules were primarily nuclear. By contrast, in samples collected post mortem, they were mainly cytosolic. Cyclin-D1 was detected only in beta cells whereas cyclin-D3 was detected in both alpha and beta cells. The proportion of donors who were immunopositive for cyclin-D1 declined from $71 \%$ in controls
\end{abstract}

Electronic supplementary material The online version of this article (doi:10.1007/s00125-015-3645-1) contains peer-reviewed but unedited supplementary material, which is available to authorised users.

Noel G. Morgan

n.g.morgan@exeter.ac.uk

1 Institute of Biomedical \& Clinical Science, University of Exeter Medical School, RILD Building, Barrack Road, Exeter EX2 5DW, UK to $30 \%$ in those with type 1 diabetes. Cyclin-D3 was present in the islets of the majority of donors in both groups.

Conclusions/interpretation The subcellular localisation of cyclin-D molecules varies according to the status of the donor. Both cyclin-D1 and -D3 can be found in the nuclei of human islet cells in situ.

Keywords Beta cell $\cdot$ Cell cycle $\cdot$ Cyclin-D molecules . Immunofluorescence staining - Immunohistochemistry . Proliferation · Type 1 diabetes

\author{
Abbreviations \\ HRP Horseradish peroxidase \\ nPOD Network of Pancreatic Organ Donors with Diabetes
}

\section{Introduction}

Human beta cells are destroyed selectively by autoreactive immune cells during the progression to type 1 diabetes, leading to life-long insulin insufficiency and a requirement for exogenous insulin replacement to maintain glucose homeostasis [1-4]. Despite this, it has become clear that beta cell loss is not always absolute in type 1 diabetes and that some patients can retain a proportion of functional beta cells, even many years after diagnosis [5-7]. The reasons for this are unclear and the origin of these residual beta cells is not understood although, intriguingly, it has been shown that islet endocrine cell proliferation is dramatically increased in response to islet inflammation in patients with recent-onset type 1 diabetes [8]. One interpretation of these data is that certain immune mediators may be capable of promoting beta cell replication in inflamed islets. This raises the possibility of targeted 
enhancement of beta cell proliferation as a therapeutic approach in certain patients. However, before such strategies can be considered, it is critical that a more complete understanding of the factors that control beta cell proliferation is gained. In particular, it is widely understood that in healthy individuals beta cells enter a state of quiescence during the immediate postnatal period, such that the rate of beta cell proliferation is normally maintained at a vanishingly low level throughout the later stages of life [9-11]. The reasons for this are unclear, but it has been suggested that beta cells are atypical in that they are able to regulate the subcellular distribution of key proteins that control their entry into, and progression through, the cell cycle $[9,12]$. These include various members of the family of cyclin-D molecules which have been detected mainly within the cytosolic compartment of human beta cells in isolated islets, rather than in the nucleus [12].

As we have previously found that endocrine cells within the inflamed islets of patients with type 1 diabetes can be induced to proliferate [8], we considered the possibility that this could reflect a change in the subcellular localisation of cyclin-D molecules, given that these proteins play an important role in controlling the $\mathrm{G} 1 / \mathrm{S}$ phase transition $[9,12,13]$. Accordingly, we set out to study the subcellular distribution of cyclin-D1, -D2 and -D3 in islet cells using pancreatic samples available from two collections: a well-characterised UK cohort $[8,14,15]$ and the network of Pancreatic Organ Donors with Diabetes (nPOD) collection [16]. The initial results were surprising, as the subcellular localisation of cyclin-D molecules differed from that reported previously in isolated human islets $[9,12,13]$. Therefore, we proceeded to evaluate this phenomenon in more detail using pancreatic samples from control donors (without diabetes). We also studied the distribution of the proteins in pancreases obtained from autoantibody-positive donors who had not progressed to diabetes and patients with type 1 diabetes.

\section{Methods}

Pancreatic specimens Formalin-fixed paraffin-embedded pancreatic specimens were available from two biobanks: the nPOD collection [16] and a historical collection from the UK $[8,14,15]$, studied with approval from Greater Glasgow NHS Research Ethics Committee. To evaluate the subcellular localisation of cyclin-D molecules in pancreatic specimens in situ, a total of 32 samples were used (15 controls [seven from nPOD and eight from the UK collection]; seven autoantibody-positive donors without diabetes [all from nPOD]; and ten donors with type 1 diabetes [seven from nPOD and three from the UK collection]). The clinical characteristics of the donors are provided in electronic supplementary material [ESM] Tables 1 and 2.
Immunohistochemistry Immunohistochemistry was performed using a standard horseradish peroxidase (HRP) technique, as described $[8,14,15]$, employing a rabbit monoclonal anti-cyclin-D1 antibody (Abcam, Cambridge, UK), a mouse monoclonal anti-cyclin-D2 antibody (Abcam) or a mouse monoclonal anti-cyclin-D3 antibody (Abcam). Stained specimens were analysed by light microscopy (Nikon Corporation, Tokyo, Japan). The specificity of the antisera was confirmed using sections of formalin-fixed paraffin-embedded human tonsil $[17,18]$.

Immunofluorescence staining To monitor the cellular distribution of cyclin-D isoforms, pancreatic sections were stained with either an anti-cyclin-D3 antibody plus HRP-goat antimouse IgG and Alexa Fluor 488 tyramide (Life Technologies, Eugene, OR, USA), or an anti-cyclin-D1 antibody plus HRPgoat anti-rabbit $\operatorname{IgG}$ and Alexa Fluor 488 tyramide. The tyramide amplification steps were used to enhance the fluorescence signal and were performed according to the manufacturer's instructions (Life Technologies). Pancreatic sections were co-stained with an anti-glucagon antibody raised in either mouse or rabbit (each from Abcam) and with guinea pig anti-insulin (Dako, Ely, UK) plus relevant secondary antibodies labelled with Alexa Fluor 568 and Alexa Fluor 647 (Life Technologies), respectively. Images were captured under fluorescence illumination using a Leica AF6000 microscope (Leica, Milton Keynes, UK).

\section{Results}

Subcellular localisation of the various cyclin-D isoforms in human islets varies among donors Initially, immunohistochemical approaches were employed to determine the subcellular localisation of the various cyclin-D isoforms in human islets in situ. Cyclin-D2 immunopositivity was present in the majority of islet cells and was localised in the cytosolic ('nonnuclear') compartment in all control pancreatic samples examined (Fig. 1c, d); the intensity of labelling was variable and it was only very weakly detected in some samples. Surprisingly, we found that the subcellular localisation of cyclin-D1 and -D3 differed between donors. These molecules were predominantly located in the cytosolic compartment of islet cells in some control pancreatic samples, but were exclusively nuclear in others (Fig. 1a, b, e, f). It was also clear that not all islet cells were stained when the cyclin molecules were detected in either the nucleus or cytosol, suggesting that the distribution of cyclin-D1 and -D3 is not uniform among islet cells.

Subcellular localisation of cyclin-D1 and -D3 in human islets varies according to donor status To evaluate the subcellular distribution more systematically, cyclin-D1 and -D3 were immunostained in 15 different control pancreases 


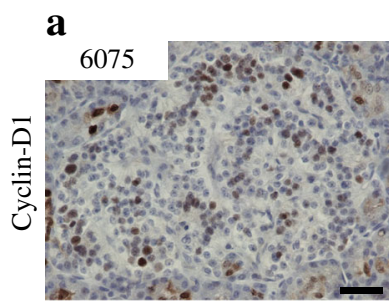

b
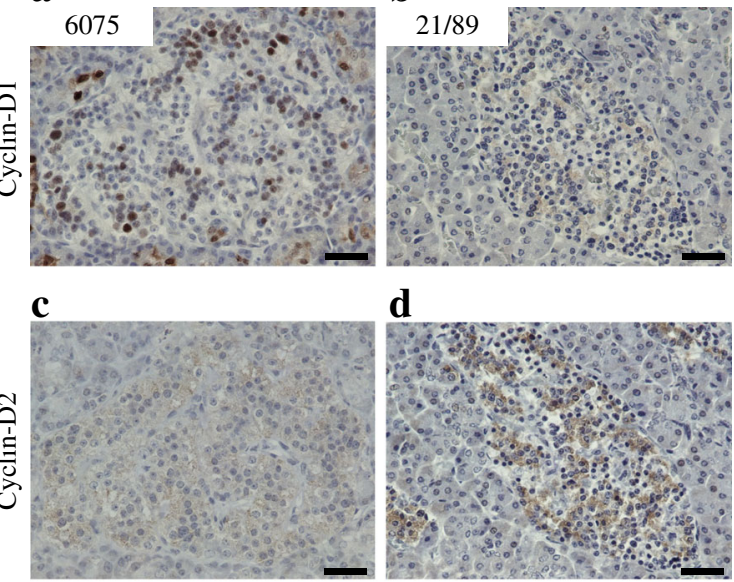

d
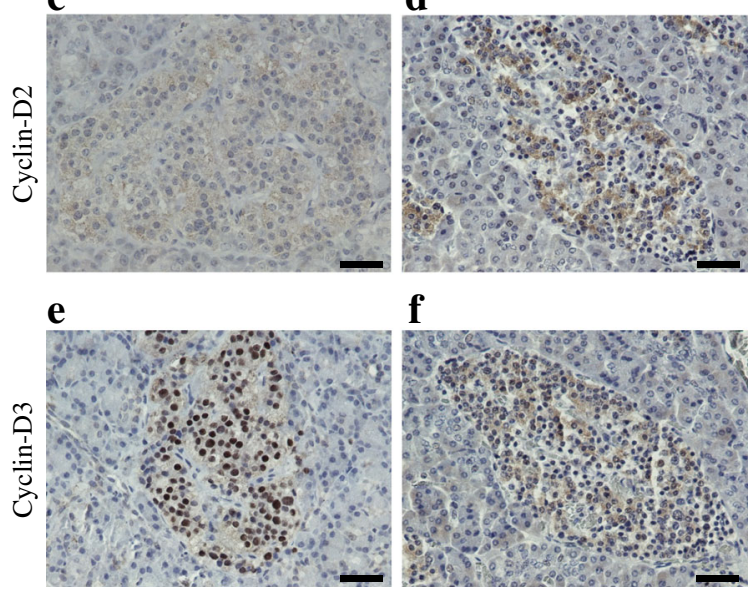

f

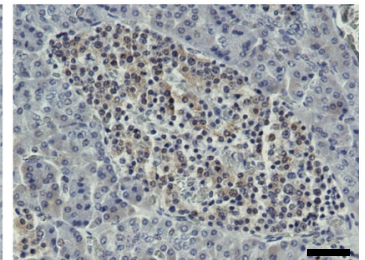

Fig. 1 The subcellular localisation of the various cyclin-D isoforms in human islets labelled in situ. Immunohistochemical approaches were employed to determine the subcellular localisation of cyclin-D1 (a, b), cyclin-D2 (c, d) and cyclin-D3 (e, f) in pancreatic specimens obtained from control donors. Case numbers are shown in the upper left. Scale bars, $50 \mu \mathrm{m}$

(Table 1) from the UK and nPOD collections. The donor groups were subdivided into those from whom the gland was recovered post mortem and those who were heartbeating at the time of organ donation. This revealed an important difference in that the distribution of cyclin-D1 and -D3 varied mainly according to the donor status but not according to the origin of the sample. Cyclin-D3 was found exclusively within islet cell nuclei in pancreases recovered from heartbeating donors (whether from the nPOD or the UK collection; Fig. 2a, c, e; Table 1) although, as noted above, not all islet cells were immunopositive. However, while a similar nuclear distribution was seen in the islet cells of two pancreases recovered post mortem, cyclin-D3 was distributed outside the nucleus of the islet cells in the majority of these specimens (five of seven; Fig. 2b, d, f and Table 1). Similarly, cyclin-D1 was mainly detected in the nuclei of islet cells in pancreases recovered from heart-beating donors, whereas it was either mainly restricted to the cytosolic compartment, or was absent, from those organs that were harvested post mortem (Table 1). Re-visiting the examples shown in Fig. 1 reinforced these conclusions. Thus, both cyclin-D1 and -D3 were detected in islet cell nuclei in case 6075 , a heart-beating donor, whereas they were localised outside the nucleus in case $21 / 89$, a post mortem donor (Fig. 1). We also confirmed that the localisation of cyclin-D2 did not vary according to the donor status among the expanded group of organ donors and was always located outside the nucleus of islet cells when detected (data not presented).

Cellular localisation of cyclin-D1 and -D3 in human islets of control donors To evaluate the cellular localisation of cyclin-D1 and -D3 in the major islet endocrine cell types, immunofluorescence analysis was performed. Cyclin-D1 and -D3 were stained in parallel with insulin and glucagon in triple-labelling experiments. Pancreas specimens from the nPOD collection were employed for these studies (Table 1). With the exception of one case (6013) where no staining was detected, cyclin-D1 was localised exclusively to insulinimmunopositive cells (beta cells), whereas those expressing glucagon (alpha cells) were unstained (Fig. 3a). In control pancreases, approximately $30 \%$ of beta cells were stained positively for cyclin-D1, although this varied somewhat between patients (Table 1).

Unlike cyclin-D1, cyclin-D3 was present in both alpha and beta cells (Fig. 3b) and the majority of both cell types were immunopositive in control pancreases (Table 1). As found for cyclin-D1, the precise proportion varied between donors.

Cellular localisation of cyclin-D1 and -D3 in human islets of autoantibody-positive donors and those with type 1 diabetes We previously reported that endocrine cells within the inflamed islets of various patients with type 1 diabetes can be induced to proliferate $[8,15]$ and we therefore evaluated the subcellular localisation of cyclin-D molecules in these samples. We also studied a group of patients who were autoantibody positive (but who did not have overt type 1 diabetes) at the time of death. A total of seven autoantibody-positive donors were examined, together with ten donors with type 1 diabetes (seven heart-beating and three post mortem). As shown in Table 1, cyclin-D1 was detected in a total of ten of $14(71 \%)$ control donors and, as expected, its precise subcellular distribution varied according to donor status. Among the group of autoantibody-positive donors, cyclin-D1 was nuclear when present (Fig. 4a) but the frequency with which it was detected in the islets was reduced by comparison with controls (four of seven donors [57\%] were immunopositive; Table 2). Among the donors with type 1 diabetes, immunopositivity for cyclin-D1 was reduced still further and it was absent from the islets in some samples (Fig. 4b). Overall, cyclin-D1 was detected in the islet cells of only three of ten donors with type 1 diabetes (30\%; Table 2). The decline in expression of cyclinD1 in the heart-beating autoantibody-positive and type 1 diabetes donors did not correlate directly with a loss of beta cells from the islets of these patients as insulin immunoreactivity was retained in at least some islets in 15 of the 17 cases studied, irrespective of the presence or absence of cyclin-D1 (data not shown). 
Table 1 The extent of expression of cyclin-D1 and -D3 in islets from heart-beating or post mortem control donors

\begin{tabular}{lllcc}
\hline Case number & Donor status & Source & Cyclin-D1 & Cyclin-D3 \\
\hline 6075 & Heart-beating & nPOD & ++ & +++ \\
6047 & Heart-beating & nPOD & + & ++ \\
6099 & Heart-beating & nPOD & + & +++ \\
6095 & Heart-beating & nPOD & + & ++ \\
6013 & Heart-beating & nPOD & NS & ++ \\
6024 & Heart-beating & nPOD & + & +++ \\
6096 & Heart-beating & nPOD & Not performed & +++ \\
16701 & Heart-beating & UK & + & +++ \\
$21 / 89$ & Post mortem & UK & ++ & +++ \\
$191 / 67$ & Post mortem & UK & ++ & + \\
$333 / 66$ & Post mortem & UK & + & +++ \\
$315 / 89$ & Post mortem & UK & + & + \\
$150 / 88$ & Post mortem & UK & NS & + \\
$485 / 88$ & Post mortem & UK & NS & + \\
$242 / 89$ & Post mortem & UK & NS & + \\
\hline
\end{tabular}

The symbols define the proportion of islets having endocrine cells that stained positively for the relevant protein in either the nuclear (green) or cytosolic (red) compartments. Yellow indicates that no islet staining was observed

Islet cells stained:,$+ 1-30 \% ;++, 31-60 \% ;+++,>60 \%$

NS, no staining

By contrast with cyclin-D1, cyclin-D3 expression did not decline within the islets of the autoantibody-positive and type 1 diabetes groups but, once again, its subcellular
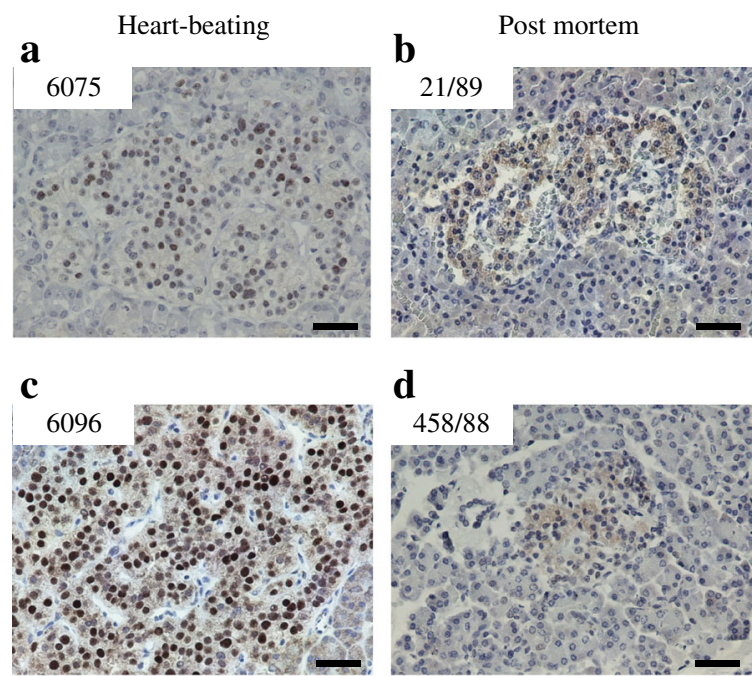

d

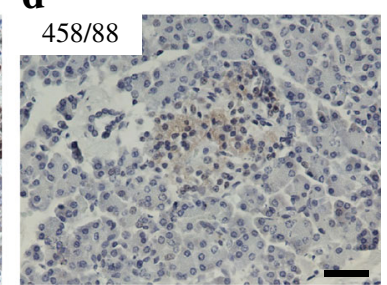

e

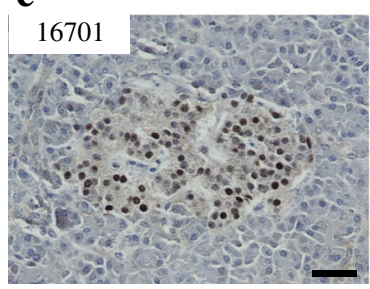

f

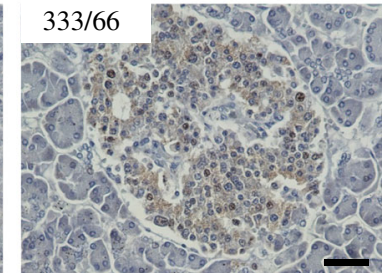

Fig. 2 The subcellular localisation of cyclin-D3 in human islets differs according to the status of the donors. Immunohistochemical approaches were employed to determine the subcellular localisation of cyclin-D3 in pancreas specimens obtained either from heart-beating organ donors (a, c, e) or post mortem $(\mathbf{b}, \mathbf{d}, \mathbf{f})$. Case numbers are shown in the upper left of each image. Scale bars, $50 \mu \mathrm{m}$ localisation varied primarily according to donor status (Figs 3b, 5a, b and Table 2).

We next examined the distribution of cyclin-D1 and -D3 in the islets of three donors with type 1 diabetes (Sc41, Sc115, E514; Table 2) which had been shown in our previous report [8] to contain proliferating beta cells. In all three cases, cyclinD3 was mainly localised within the cytosol and cyclin-D1 levels were low but could be detected in either the cytosolic or nuclear compartment, depending on the case.

\section{Discussion}

Human pancreatic beta cells undergo an age-dependent regulation of their proliferative activity, which declines markedly during the early years of life [19-21]. This reduced proliferative capacity then appears to be maintained such that estimates of the 'age' of resident beta cells in adult human islets (for example, by analysis of lipofuscin content) suggest that they are long-lived and not renewed by regular rounds of mitosis $[11,22]$. Despite this, there are circumstances when proliferation can be re-initiated. Thus, we have demonstrated that beta cell proliferation is increased some tenfold in the inflamed islets of children with recent-onset type 1 diabetes compared with age-matched controls $[8,15]$. Therefore, although beta cell proliferation may be rare beyond the early postnatal period, it seems that the process can be re-activated under appropriate conditions. As such, these observations offer the potential that beta cells might be targeted as a means to replenish the population by enhanced mitosis in patients where loss has occurred. However, at present, this is precluded by a lack of understanding of the factors that regulate their proliferative capacity. 
Fig. 3 The cellular localisation of cyclin-D1 and -D3 in human islets labelled in situ. Immunofluorescence staining was performed to reveal the cellular localisation of cyclin-D1 (a) and cyclin-D3 (b) within islet endocrine cells. Cyclin-D1 (green; a) or cyclin-D3 (green; b) were stained in combination with insulin (light blue; $\mathbf{a}, \mathbf{b}$ ) and glucagon (red; a, b). Case numbers are shown in the upper left. Scale bars, $25 \mu \mathrm{m}$ $\mathbf{a}$
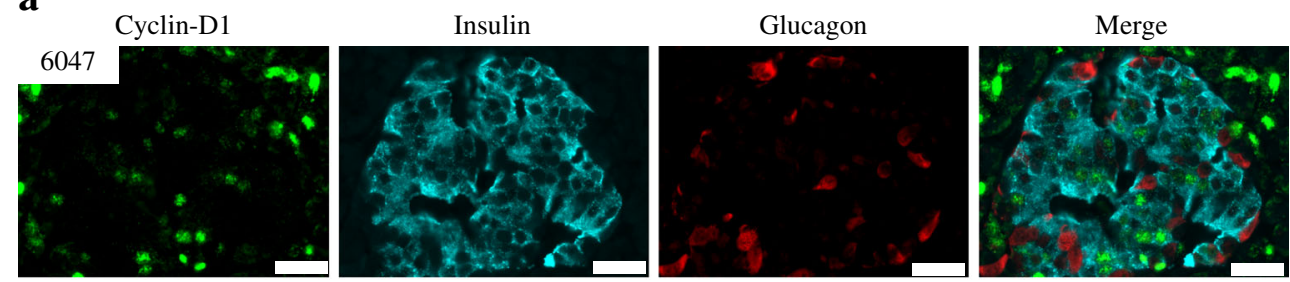

b

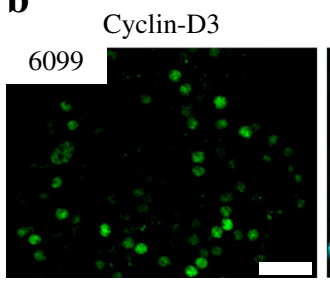

Insulin
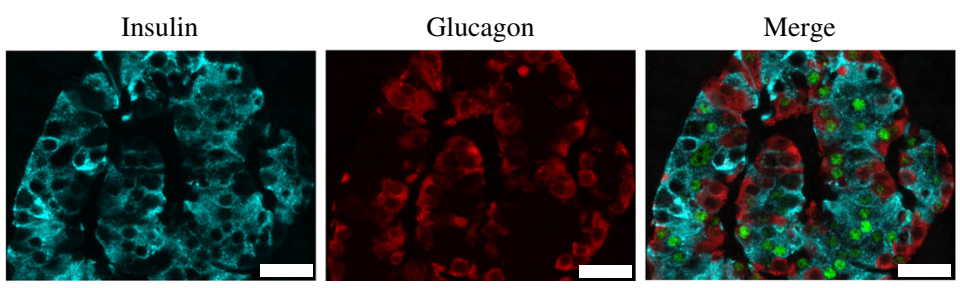

In order to initiate mitosis, it is suggested that a number of key regulatory proteins must be present within the nuclei of beta cells, including various cyclin-D molecules and cyclindependent kinases which control progression through the cell cycle $[9,12,13]$. Recent studies undertaken mainly with isolated human islet preparations have suggested that, unusually, many of these factors are not resident in the nuclei of beta cells but, rather, they appear to be sequestered in the cytosolic compartment $[9,12,13]$. As such, this may account for the attenuated rate of proliferation seen in adult beta cells. We were surprised, therefore, when analysing the distribution of cyclin$\mathrm{D}$ molecules in human islets retained in situ in pancreatic sections, to find circumstances where some of these proteins are predominantly nuclear. We are, however, aware that Köhler et al have also reported the nuclear localisation of cyclinD3 in islet sections [23]. Further investigation revealed a marked difference in the distribution of cyclin-D1 and -D3 according to the status of the pancreas donor. In heartbeating donors, both cyclin-D1 and -D3 were resident exclusively in islet cell nuclei, whereas, in glands from post mortem donors, they were mainly localised within the cytosol. Interestingly, both patterns could be seen in pancreases available from the historical UK collection whereas, in nPOD cases, cyclin-D1 and -D3 were invariably nuclear. This may imply that the differences in subcellular localisation reflect a cohortspecific phenomenon; while we cannot exclude this possibility completely, certain evidence argues against this explanation. In the UK collection, cyclin-D1 and -D3 displayed a nuclear localisation in the islets of a heart-beating donor (16701) and at least two post mortem samples contained islets with nuclear cyclin-D3 (Table 1). Importantly, these data reveal that cyclin-D molecules can reside in the nuclear compartment of islet cells in situ. They also suggest the possibility that, during the post mortem period, some cyclin-D isoforms

\section{a}

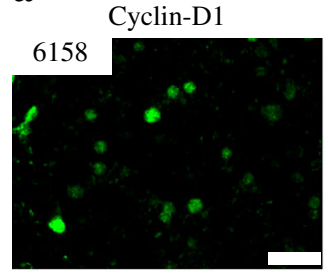

b
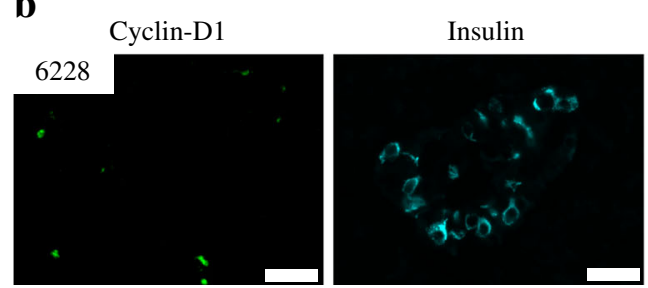

Fig. 4 The cellular localisation of cyclin-D1 in the islets of autoantibodypositive donors and those with type 1 diabetes. Immunofluorescence staining was performed to reveal the cellular localisation of cyclin-D1 in the pancreas specimens obtained from either autoantibody-positive
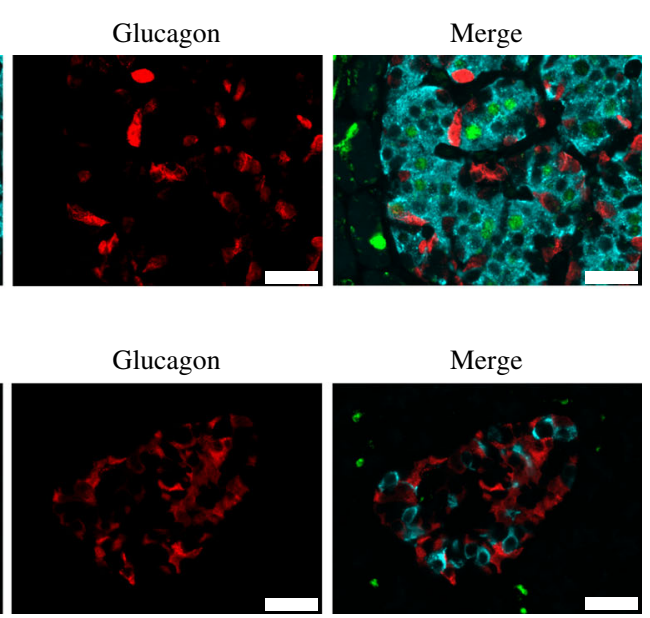

donors (a) or those with type 1 diabetes (b). Cyclin-D1 (green; a, b) was stained in combination with insulin (light blue; $\mathbf{a}, \mathbf{b}$ ) and glucagon (red; a, b). Case numbers are shown in the upper left. Scale bars, $25 \mu \mathrm{m}$ 
Table 2 The extent of expression of cyclin-D1 and -D3 in islets from heart-beating or post mortem autoantibody-positive donors and those with type 1 diabetes

\begin{tabular}{llllcc}
\hline Case number & Disease & Donor status & Source & Cyclin-D1 & Cyclin-D3 \\
\hline 6002 & Autoantibody-positive & Heart-beating & nPOD & NS & +++ \\
6023 & Autoantibody-positive & Heart-beating & nPOD & NS & ++ \\
6080 & Autoantibody-positive & Heart-beating & nPOD & NS & ++ \\
6123 & Autoantibody-positive & Heart-beating & nPOD & + & + \\
6158 & Autoantibody-positive & Heart-beating & nPOD & ++ & +++ \\
6197 & Autoantibody-positive & Heart-beating & nPOD & + & +++ \\
6267 & Autoantibody-positive & Heart-beating & nPOD & + & +++ \\
6026 & Type 1 diabetes & Heart-beating & nPOD & NS & ++ \\
6148 & Type 1 diabetes & Heart-beating & nPOD & NS & + \\
6209 & Type 1 diabetes & Post mortem & nPOD & NS & + \\
6212 & Type 1 diabetes & Heart-beating & nPOD & + & +++ \\
6228 & Type 1 diabetes & Heart-beating & nPOD & NS & ++ \\
6243 & Type 1 diabetes & Heart-beating & nPOD & ++ & +++ \\
6245 & Type 1 diabetes & Heart-beating & nPOD & NS & +++ \\
Sc41 & Type 1 diabetes & Post mortem & UK & NS & ++ \\
Sc115 & Type 1 diabetes & Post mortem & UK & + & ++ \\
E514 & Type 1 diabetes & Post mortem & UK & NS & + \\
\hline
\end{tabular}

The symbols define the proportion of islets having endocrine cells which stained positively for the relevant protein in either the nuclear (green) or cytosolic (red) compartments. Yellow indicates that no islet staining was observed

Islet cells stained:,$+ 1-30 \% ;++, 31-60 \% ;+++,>60 \%$

NS, no staining

tend to re-distribute to the cytosol, although we accept that such redistribution has not been verified formally and that this process cannot be interrogated directly by examination of tissue sections. It is also of interest to note, however, that cyclinD2 was invariably cytosolic in all samples where it was detected. This could reflect an even more rapid transit from nucleus to cytosol in the case of cyclin-D2 than for the other cyclin-D isoforms studied or, conceivably, this protein may be typically retained outside the nucleus in human islet cells.

One important consideration in interpreting the present findings is the age of the patients at the time of death, as younger children might be expected to retain a higher proportion of beta cells with the capacity to proliferate (and the cyclin-D molecules might then be expected to display a preferential nuclear localisation) [19-21]. However, in the present study, some of the youngest individuals (who were younger than 4 years of age) had cytosolic localisation of the various cyclin-D molecules. Moreover, many of the donors in whom cyclin-D1 and/ or -D3 were nuclear had reached maturity and were well beyond the age at which beta cell proliferation declines in early childhood. Therefore, one important conclusion from this work is that cyclin-D1 and -D3 can be retained in the nuclei of human beta cells in patients who are beyond the age at which beta cell quiescence occurs. This implies that factors additional to the subcellular localisation of these particular molecules must determine the proliferative capacity of these cells.

It is also important to consider an alternative possibility in the light of observations made by In't Veld et al. These authors made the striking observation that maintenance of organ donors on prolonged life support within intensive care units prior to harvesting of the pancreas can lead to an increased level of beta cell replication on subsequent organ retrieval [24]. As replication is likely to require the nuclear localisation of cell cycle regulators such as cyclin-D1 and -D3, it is possible that the increased replication rate reflects the transit of these molecules into the nucleus during the period prior to organ retrieval. On this basis, it might be suggested that, in our study, the disposition of cyclin-D molecules in the islets of the heartbeating donors is as much a reflection of the period spent on life support prior to harvesting of the pancreas as to the true situation in vivo. While we cannot exclude this completely, the fact that we were able to find post mortem donors with either cytosolic or nuclear cyclin-D1 and -D3 (Table 2) supports the proposition that these proteins can be found within the nucleus of islet cells in individuals who were not maintained on life support systems prior to death. Moreover, in the study by In't Veld et al, it was found that the islets of donors aged below 25 years had the highest rates of beta cell replication while these high rates were much less frequent in older donors maintained on life support. In our study, six of the heart-beating donors were aged over 25 years (range 3969 years) and all showed nuclear localisation of cyclin-D3.

In drawing these conclusions, we emphasise that this study cannot define the factors that influence the distribution of the cyclin-D isoforms in human islet cells. One obvious possibility is that the extent (and period) of tissue hypoxia is relevant. In this scenario, glands harvested from heart-beating donors might be considered less likely to sustain long periods of hypoxia than those recovered post mortem, which could then account for some of the differences observed. In support of this, Xu et al have shown that periods of hypoxia can influence the distribution of cyclin-D molecules in mouse beta cells [25] 
Fig. 5 The cellular localisation of cyclin-D3 in the islets of autoantibody-positive donors and those with type 1 diabetes. Immunofluorescence staining was performed to reveal the cellular localisation of cyclin-D3 in pancreatic specimens obtained from either autoantibody-positive donors (a) or those with type 1 diabetes (b). Cyclin-D3 (green; a, b) was stained in combination with insulin (light blue; a, b) and glucagon (red; a, b). Case numbers are shown in the upper left. Scale bars, $25 \mu \mathrm{m}$ a
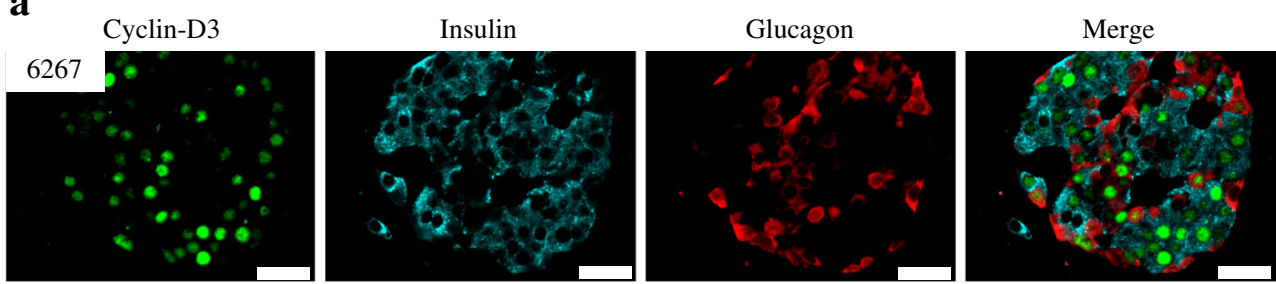

b

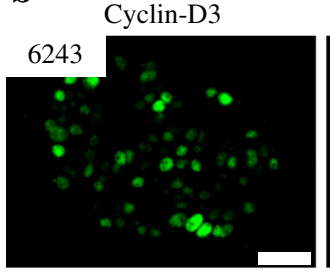

Insulin

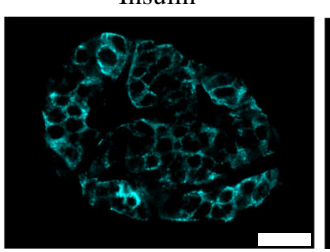

Glucagon

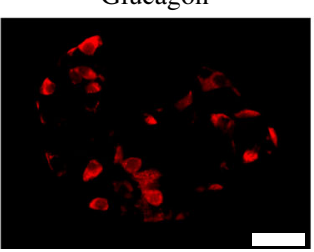

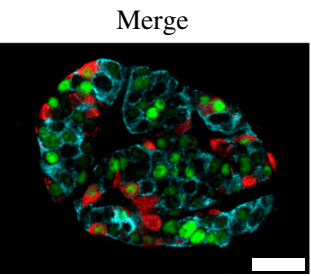

although, in this case, hypoxic conditions favoured the accumulation of cyclin-D2 within the nucleus. Extending these considerations, it is important to note that the conditions experienced by human beta cells during the process of islet isolation and culture might also be conducive to a redistribution and/or degradation of cyclin-D molecules. Indeed, in preliminary work we verified this by monitoring cyclin-D3 expression in a single preparation of human islets isolated from a heart-beating donor and maintained in tissue culture. Within $24 \mathrm{~h}$ of isolation, cyclin-D3 was exclusively cytosolic in the islet cells and by 8 days of culture it was undetectable within the islet cells (K. Taniguchi, M. A. Russell, S. J. Richardson, N. G. Morgan; unpublished observations). This suggests very strongly that the localisation and stability of cell cycle regulators in human islet cells can be influenced by extrinsic factors impinging on the cells during the post mortem period and after islet isolation.

As we have demonstrated in previous work that the rate of islet cell proliferation is elevated in patients with recent-onset type 1 diabetes (as judged by immunostaining of the proliferation markers Ki67 and minichromosome maintenance complex component 2 (MCM-2)) [8], we considered it important to extend the present study to examine the distribution of cyclin-D1 and -D3 in the islet cells of some of these patients. This revealed that the expression of cyclin-D1 declines in the majority of donors with type 1 diabetes and that this protein was also reduced in the islets of a proportion of those who were autoantibody positive at the time of death. This implies that loss of cyclin-D1 may accompany the ongoing process of islet autoimmunity in humans, although the significance of this observation remains to be established. By contrast, the levels of cyclin-D3 were maintained in the islet cells of autoantibody-positive donors and those with type 1 diabetes, although, as expected, its precise subcellular distribution varied according to the donor status. Indeed, in three type 1 diabetes cases from the UK collection (Sc41, Sc115, E514) selected specifically because they had displayed enhanced rates of islet cell proliferation in our earlier analysis [8], we found that cyclin-D3 was localised to the cytosol (Table 2). Moreover, cyclin-D1 was absent from the islets of two of these cases (Table 2) at the time of tissue fixation. These findings add weight to the concept that cyclin-D isoforms may redistribute and/or become degraded during the post mortem period in human islet cells as it is likely that cyclin-D3 (and possibly cyclin-D1) will have been located in the nuclei of the islet cells prior to death, in order to drive the proliferative response. The results also imply that the proliferation marker, Ki67, preferentially retained its nuclear distribution in the islet cells after the death of these patients, even under conditions when cyclin-D isoforms were influenced to migrate into the cytosol (and/or were degraded).

Taken together, the current studies suggest that the localisation of cyclin-D isoforms within pancreatic beta cells varies according to the status of the donor tissue. The results imply that both cyclin-D1 and -D3 are normally retained within the nucleus in situ in beta cells but that they may migrate to the cytosol during the early post mortem period. Ultimately, cyclin-D1 might then be degraded. By contrast, cyclin-D3 appears more stable and is still detected in pancreatic samples from which cyclin-D1 has been lost. Overall, our results suggest that caution should be exercised when interpreting the distribution of cell cycle regulators in human islet cells during immunostaining studies (and in isolated human islet preparations) as this can vary markedly according to donor status.

Funding The work was supported by funding from the European Union's Seventh Framework Programme PEVNET [FP7/2007-2013] under grant agreement number 261441. Additional support was from an European Foundation for the Study of Diabetes (EFSD)/Lilly Fellowship to MAR and a Juvenile Diabetes Research Foundation (JDRF) Career Development Award to SJR. The research was also performed with the support of nPOD, a collaborative type 1 diabetes research project sponsored by the JDRF International and with a JDRF research grant awarded to the nPOD-Virus consortium. Organ procurement organisations (OPOs) 
partnering with nPOD to provide research resources are listed at www. jdrfnpod.org/our-partners.php.

Duality of interest The authors declare that there is no duality of interest associated with this manuscript.

Contribution statement KT, SJR and MAR performed experiments and interpreted data. All authors contributed to study design. KT and NGM wrote the manuscript and all authors were involved in revising the article critically for important intellectual content. All authors agreed the final version. NGM is responsible for the integrity of the work as a whole.

\section{References}

1. Roep BO, Tree TI (2014) Immune modulation in humans: implications for type 1 diabetes mellitus. Nat Rev Endocrinol 10:229-242

2. Eisenbarth GS (1986) Type I diabetes mellitus. A chronic autoimmune disease. N Engl J Med 314:1360-1368

3. Pickup JC, Keen H, Parsons JA, Alberti KG (1978) Continuous subcutaneous insulin infusion: an approach to achieving normoglycaemia. Br Med J 1:204-207

4. Tamborlane WV, Sherwin RS, Genel M, Felig P (1979) Reduction to normal of plasma glucose in juvenile diabetes by subcutaneous administration of insulin with a portable infusion pump. N Engl J Med 300:573-578

5. Keenan HA, Sun JK, Levine J et al (2010) Residual insulin production and pancreatic beta-cell turnover after 50 years of diabetes: Joslin Medalist Study. Diabetes 59:2846-2853

6. Oram RA, Jones AG, Besser RE et al (2014) The majority of patients with long-duration type 1 diabetes are insulin microsecretors and have functioning beta cells. Diabetologia 57:187-191

7. Davis AK, DuBose SN, Haller MJ et al (2015) Prevalence of detectable C-peptide according to age at diagnosis and duration of type 1 diabetes. Diabetes Care 38:476-481

8. Willcox A, Richardson SJ, Bone AJ, Foulis AK, Morgan NG (2010) Evidence of increased islet cell proliferation in patients with recent-onset type 1 diabetes. Diabetologia 53:2020-2028

9. Fiaschi-Taesch NM, Salim F, Kleinberger J et al (2010) Induction of human beta-cell proliferation and engraftment using a single G1/S regulatory molecule, cdk6. Diabetes 59:1926-1936

10. Stein J, Milewski WM, Dey A (2013) The negative cell cycle regulators, p27(Kip1), p18(Ink4c), and GSK-3, play critical role in maintaining quiescence of adult human pancreatic beta-cells and restrict their ability to proliferate. Islets 5:156-169

11. Cnop M, Igoillo-Esteve M, Hughes SJ, Walker JN, Cnop I, Clark A (2011) Longevity of human islet alpha- and beta-cells. Diabetes Obes Metab 13(Suppl 1):39-46
12. Fiaschi-Taesch NM, Kleinberger JW, Salim FG et al (2013) Human pancreatic beta-cell G1/S molecule cell cycle atlas. Diabetes 62:2450-2459

13. Fiaschi-Taesch NM, Kleinberger JW, Salim FG et al (2013) Cytoplasmic-nuclear trafficking of $\mathrm{G} 1 / \mathrm{S}$ cell cycle molecules and adult human beta-cell replication: a revised model of human betacell G1/S control. Diabetes 62:2460-2470

14. Richardson SJ, Willcox A, Bone AJ, Foulis AK, Morgan NG (2009) The prevalence of enteroviral capsid protein vp1 immunostaining in pancreatic islets in human type 1 diabetes. Diabetologia 52:1143-1151

15. Willcox A, Richardson SJ, Bone AJ, Foulis AK, Morgan NG (2011) Immunohistochemical analysis of the relationship between islet cell proliferation and the production of the enteroviral capsid protein, VP1, in the islets of patients with recent-onset type 1 diabetes. Diabetologia 54:2417-2420

16. Campbell-Thompson M, Wasserfall C, Kaddis J et al (2012) Network for Pancreatic Organ Donors with Diabetes (nPOD): developing a tissue biobank for type 1 diabetes. Diabetes Metab Res Rev 28:608-617

17. Miranda RN, Briggs RC, Kinney MC, Veno PA, Hammer RD, Cousar JB (2000) Immunohistochemical detection of cyclin D1 using optimized conditions is highly specific for mantle cell lymphoma and hairy cell leukemia. Mod Pathol 13:1308-1314

18. Igawa T, Sato Y, Takata K et al (2011) Cyclin D2 is overexpressed in proliferation centers of chronic lymphocytic leukemia/small lymphocytic lymphoma. Cancer Sci 102:2103-2107

19. Meier JJ, Butler AE, Saisho Y et al (2008) Beta-cell replication is the primary mechanism subserving the postnatal expansion of betacell mass in humans. Diabetes 57:1584-1594

20. Perl S, Kushner JA, Buchholz BA et al (2010) Significant human beta-cell turnover is limited to the first three decades of life as determined by in vivo thymidine analog incorporation and radiocarbon dating. J Clin Endocrinol Metab 95:E234-E239

21. Gregg BE, Moore PC, Demozay D et al (2012) Formation of a human beta-cell population within pancreatic islets is set early in life. J Clin Endocrinol Metab 97:3197-3206

22. Cnop M, Hughes SJ, Igoillo-Esteve M et al (2010) The long lifespan and low turnover of human islet beta cells estimated by mathematical modelling of lipofuscin accumulation. Diabetologia 53:321-330

23. Köhler CU, Olewinski M, Tannapfel A, Schmidt WE, Fritsch H, Meier JJ (2011) Cell cycle control of beta-cell replication in the prenatal and postnatal human pancreas. Am J Physiol Endocrinol Metab 300:E221-E230

24. In't Veld P, de Munck N, van Belle K et al (2010) Beta-cell replication is increased in donor organs from young patients after prolonged life support. Diabetes 59:1702-1708

25. Xu J, Long YS, Gozal D, Epstein PN (2009) Beta-cell death and proliferation after intermittent hypoxia: role of oxidative stress. Free Radic Biol Med 46:783-790 